\title{
EXPERIMENTAL METHODOLOGY FOR ACOUSTIC DIAGNOSTICS OF SHOCK ABSORBERS
}

\author{
Jakub Halama ${ }^{1}$, Milan Klapkaํ, Ivan Mazůrek ${ }^{1}$ \\ ${ }^{1}$ Brno University of Technology, Faculty of Mechanical Engineering, Technická 2, 61669 Brno, Czech Republic \\ To cite this article: HALAMA JAKUB, KLAPKA MILAN, MAZU゚REK IVAN. 2018. Experimental \\ Methodology for Acoustic Diagnostics of Shock Absorbers. Acta Universitatis Agriculturae et Silviculturae \\ Mendelianae Brunensis, 66(5): 1119-1125.
}

To link to this article: https://doi.org/10.11118/actaun201866051119

\begin{abstract}
The application of acoustic measurements brings about a new diagnostic method for evaluating the conditions of shock absorbers. In shock absorber diagnostics, it is advantageous to observe and understand what phenomena occur during the working cycle in the inner tube. Using a non-destructive and non-contact method can avoid dismantling whole device. For the research of this new acoustic method, a classic sound meter, an automotive and a train shock absorber were used. FFT analysis and concurrent filtration were applied for the measurement evaluation of obtained data. It has been proven that applying acoustic methods can lead to diagnostics of aeration in the shock absorbers. A defective shock absorber changes its damping characteristics as well as noise radiation compared with the properly functioning one; these differences in noise are measurable and quantifiable. The results show that characteristics of acoustic radiation of the aerated shock absorbers relate to the shock construction type.
\end{abstract}

Keywords: automotive shock absorber, acoustic diagnostics, aeration, cavitation

\section{INTRODUCTION}

Shock absorbers are one of the essential parts of the car; they influence both driving comfort and driving safety. For a shock absorber development and for setting current parameters of damping according to requirements, it is necessary to detect what phenomena occur in the inner tube in case of some defect. Nowadays usual diagnostic method for the shock absorbers is using actuators with several sensors such as force gauges and displacement sensors. Such test can show the damping force response, which can indicate an issue. The identification of the shock absorber malfunction can be usually made accurately by dismantling the whole shock absorber and looking inside. However, this could lead to its irreversible change of behaviour or even to destruction of the sample. It is advantageous to avoid these and diagnose the shock absorber using some of the non-destructive approaches. Such methods can be found in the field of the acoustics. Analysing the differences in the acoustic radiations of properly working and defective shock absorber can lead to determining specific diagnostic criteria for various shock absorber designs. This effort results in assembly of "catalogue" of defects and their specific acoustic patterns. This paper brings several fundamental measurements with aeration (connected with cavitation) which can be used as a base for such catalogue.

Noise can radiate directly to the air from the shock absorber body or it can be transferred further to the connected chassis and radiated somewhere else as a product of shock absorbers vibrations (Lauweyrs et al., 2000). These mechanical vibrations caused by discontinuous damping are 
called high-frequency forces. The discontinuity in damping response can be connected to friction between the piston and the inner tube, opening and closing of valves (Benaziz et al., 2015; Benaziz et al., 2015) and oil behaviour flowing through these valves (Lauweyrs et al., 2000). Several studies (Lauweyrs et al., 2000; Benaziz et al., 2015; Yung et al., 2006) have shown that high-frequency forces achieve the maximum of $1 \mathrm{kHz}$, where lower frequencies have greater representation. Another shock absorber issue is cavitation which occurs at the compression phase of the cycle (Dixon, 2007). Cavitation is located near valves and is often connected with aeration. Because of the aeration, the damping force decreases which can also change the amount of radiated noise (Luo and Zhang, 2014).

For diagnostics of the shock absorbers, it is important to focus on the piston and its immediate surroundings. Moreover, the radiated noise should be observed according to the actual position of the valve. The shock absorber radiate noise can be found in low frequencies-up to $1 \mathrm{kHz}$.

Excessive noise radiation can usually reflect a wrong function of a device or a machine. Therefore, the technical diagnostics can be done by measuring the acoustic quantities, especially where non-contact methods are required. In the literature there are several studies that measure acoustic radiation of properly working shock absorbers and make a comparison to the shock absorbers with some damage.

In the 1990s there were the first attempts to identify the shock absorber noise. Lauweris (2000) made a distinction between two kinds of shock absorber noise. According to this study, air born noise was audible when the shock absorber was excited on an actuator. There was also structure-borne noise which was transferred through the car construction and radiated somewhere else. This noise was caused by damping non-linearities. Study showed a correlation between the acceleration of the shock absorber top mount and the sound pressure level. However, the noise was measured in the car interior, not directly near the shock absorber itself.
Huang (2015) investigated the differences between a properly functioning shock absorber and a shock absorber with "rattling noise". Measured sound energy of both shocks in the time-frequency domain was mainly below $1 \mathrm{kHz}$; lower frequencies were represented more often. The rattling shock absorber showed bigger noise radiation than the properly working one. But sound energy was measured in the car interior as well.

Benaziz (2015) developed a model of the shock absorber for predicting structure-borne noise. This model considered valve stiction and spring valve dynamics as possible sources of the noise. The higher acceleration level of the shock rod and piston was measured when the first spring valve opened. The frequency of acceleration occurred on a wide frequency range at that moment. This non-linearity caused structure-borne noise, which could be radiated within the acceleration frequency range. However, measuring of noise was used only for the approval of the model, not for the diagnostic purposes.

The current research describes changes of the radiated noise connected to the damping response of the shock absorber. But no study has ever focused on measuring directly the shock absorber noise for diagnostic purposes. There is no method for the assessing of proper functioning of the shocks based on the radiated noise analyzation. This paper describes the initial attempts to identify and quantify the amount of aeration from the shock absorber radiated noise. There is also the determination of the optimal diagnostic criterion for two different shock absorber designs and the description of its measuring conditions.

\section{MATERIALS AND METHODS}

The hypothesis this study tries to prove is that the analysis of the shock absorber acoustic radiation can determine type of the shock absorber defect. In the experiments, a properly functioning and an aerated shock absorber were compared. Assessment of the differences between the operation of the shock
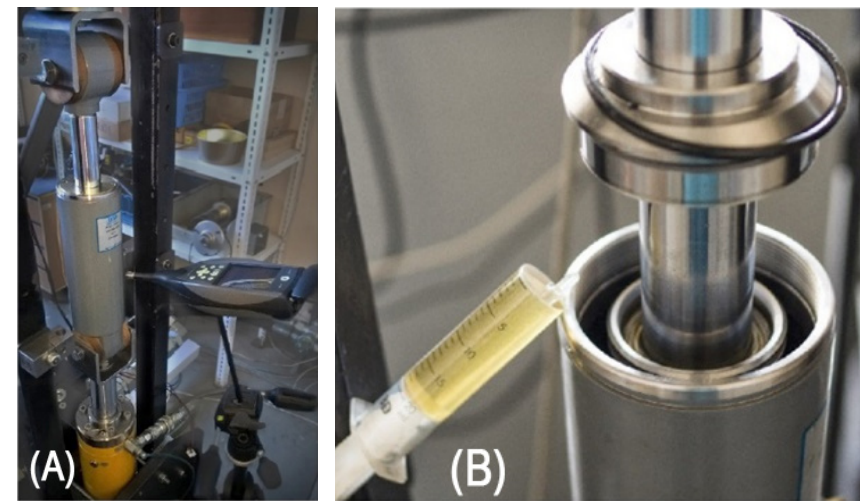

1: (A) Measuring radiated noise of the STOS shock absorber using the sound meter. (B) Aeration was caused by removing the oil from the inner tube of the shock. 
absorbers as well as determining diagnostic criteria were done by the analysis of the acoustic data.

For accurate acoustic signal analysis, the noise was measured by the Brüel and Kjær sound meter, type 2270 (Fig. 1A). Acoustic signal was further processed in the DEWETRON analyzer and evaluated in the DEWESoft software. The force gauge data and actual position of the valve were also recorded by Dewetron device to monitor the F-z curve of the shock absorber.

Two types of the shock absorbers were used for the experiments. The first one was train shock absorber R110 manufactured by the STOS company. It is a double tube shock absorber with a robust construction which should provide strong noise radiation. Its total stroke is $170 \mathrm{~mm}$, the maximum of the damping force is about $10 \mathrm{kN}$. The oil volume is $800 \mathrm{ml}$. The other shock absorber was sample of a common car shock-a double tube rear shock absorber from the Fiat 500 car. The stroke is $76 \mathrm{~mm}$ and the optimal oil volume is $127 \mathrm{ml}$. Recommended pressure of the air cushion is 3,5 bars. This Fiat shock was measured in its original design and in adjusted design called as adaptive. The adaptive version is split into two parts and can be mounted together by screw connection (Fig. 2A); there is also a reverse throttle valve for oil volume regulation and air cushion pressurization (Fig. 2B). Thus it is possible to simulate various kinds of the malfunctions easily.

The excitation was provided by a computer controlled hydraulic actuator Inova, type AH 40-150 M56. The excitation procedure was in accordance with the standard operating conditions of the shock absorbers. The excitation stroke for STOS was $32 \mathrm{~mm}$, while for Fiat shock it was $40 \mathrm{~mm}$. The interval for excitation frequency falls into 1-3 $\mathrm{Hz}$ in case of STOS, and $1-4 \mathrm{~Hz}$ in case of Fiat shock absorber; these frequencies were constant for every separate measurement. Each excitation time was $20 \mathrm{~s}$ to avoid excessive heating of the oil in both shock absorbers. The distance between the shock absorber outer casing and the microphone was $40 \mathrm{~mm}$ while the microphone was placed in the plane of the central position of the piston. Data was sampled at $20 \mathrm{kHz}$.
The examined defect of the shock absorber was excessive aeration connected with cavitation. It was caused artificially by removing exact volume of the oil (Fig. 1B). The level of aeration was managed by a gradual oil removal.

The literature review has showed that the defects of a typical automobile shock absorber were located near the piston and occurred in certain phases of the stroke. The acoustic radiation of the defects is most significant in frequencies up to $1 \mathrm{kHz}$. Therefore, the acoustic signal was transformed from the time domain to the frequency domain to determine the representation rate of the frequencies (Fast Fourier transform). The acquired frequency spectrum was divided into the distinctive frequency bands which were evaluated separately to exclude the frequencies that were not expected as typical shock absorber radiation by FIR filtration of processed dat. A sound pressure level assessment at the specific stroke phase was done by averaging dozens of the cycles which led to eliminating the irregular noise and highlighting the regular noise radiation (synchronous filtration).

\section{RESULTS}

A deeper analysis of the signal obtained from the sound meter showed differences between the properly functioning and the aerated shock absorber in a certain frequency bands. In the frequency domain, the aerated STOS shock had stronger acoustic radiation in the frequency range of $205-380 \mathrm{~Hz}$ (Fig. 3). Characteristic shock frequencies could be found in this range. In case of the Fiat shock, the original version of the shock absorber had stronger acoustic radiation in the frequency range of $255-470 \mathrm{~Hz}$ than the adaptive aerated one (Fig. 4). The differences in the frequency spectra among the different levels of aeration were not observed in the adaptive version.

Next move was to investigate relations between sound pressure level and piston displacement during working cycle. The synchronous filtration was counted and plotted into the graphs for each frequency band separately. As expected from FFT

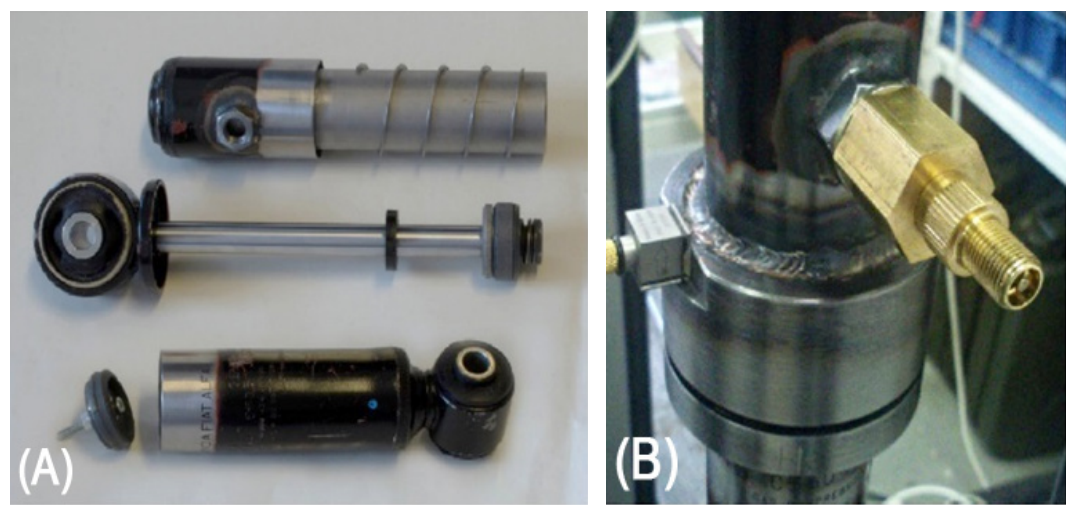

2: (A) Dismantled adaptive version of the Fiat shock absorber, meantime without welded screw connection. (B) The reverse throttle valve of the Adaptive Fiat shock. 


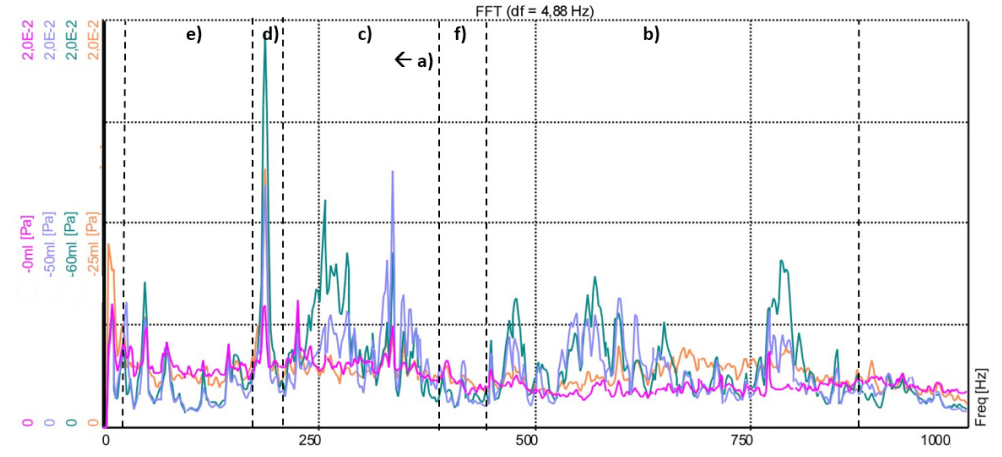

3: The frequency domain of the STOS shock absorber noise split to the separate frequency bands.

Pink curve - $0 \mathrm{ml}$ oil removed; orange $-25 \mathrm{ml}$; blue - $50 \mathrm{ml}$; green $-60 \mathrm{ml}$. a) low pass filter $380 \mathrm{~Hz}$,

b) band pass $440-860 \mathrm{~Hz}$, c) 205-380 Hz, d) $170-205 \mathrm{~Hz}$, e) $20-170 \mathrm{~Hz}$, f) $380-440 \mathrm{~Hz}$. Excitation $2 \mathrm{~Hz}$.

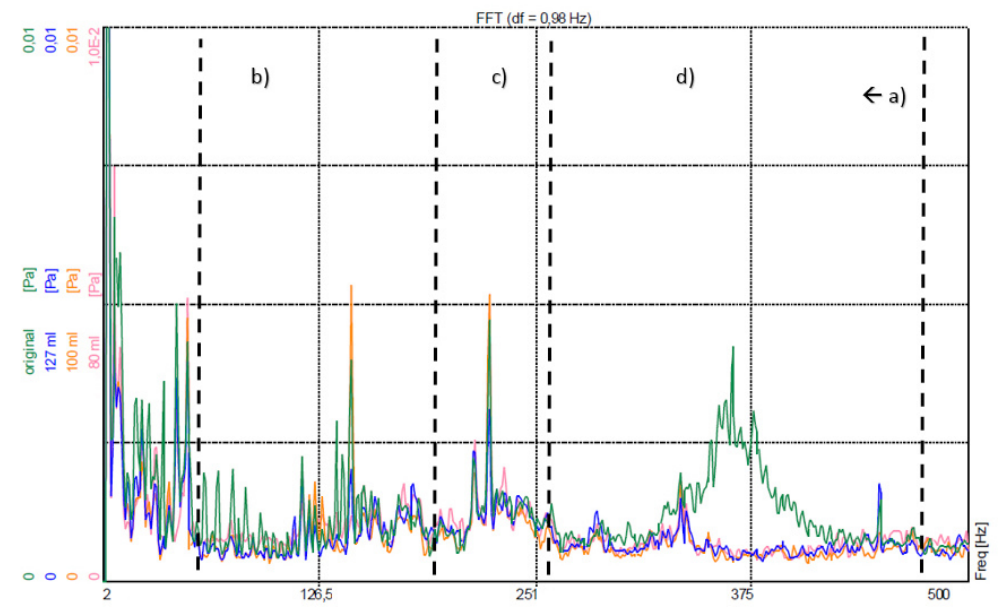

4: The frequency domain of the Fiat shock absorber noise split to the separate frequency bands.

Pink curve-adaptive, $80 \mathrm{ml}$ volume of oil; orange-adaptive, $100 \mathrm{ml}$; blue-adaptive, $127 \mathrm{ml}$; green-original. a) low pass filter $470 \mathrm{~Hz}$, b) band pass 60-195 Hz, c) $195-255 \mathrm{~Hz}$, d) 255-470 Hz. Excitation $4 \mathrm{~Hz}$.
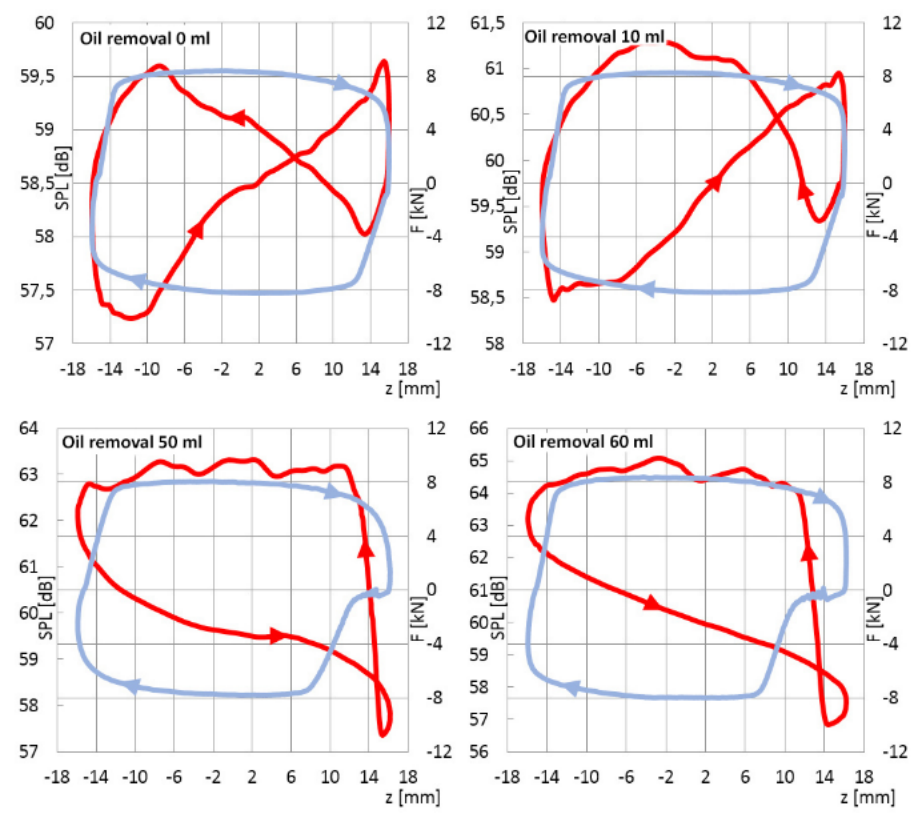

5: The F-z characteristic (blue) and the synchronous filtration of the acoustic intensity levels in dependence on the stroke (red) for the different volume of oil removal in the STOS shock absorber. Excitation $2 \mathrm{~Hz}$, frequency band 205-380 Hz. 


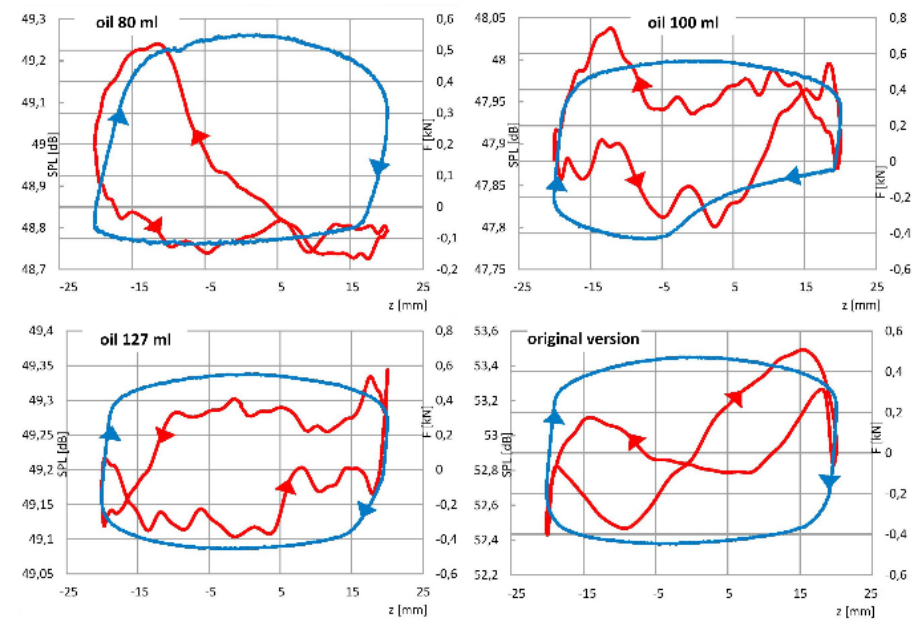

6: The F-z characteristic (blue) and the synchronous filtration of the acoustic intensity levels in dependence on the stroke (red) for the different volume of oil removal and version of the Fiat shock absorber. Excitation $3 \mathrm{~Hz}$, frequency band 255-470 Hz.
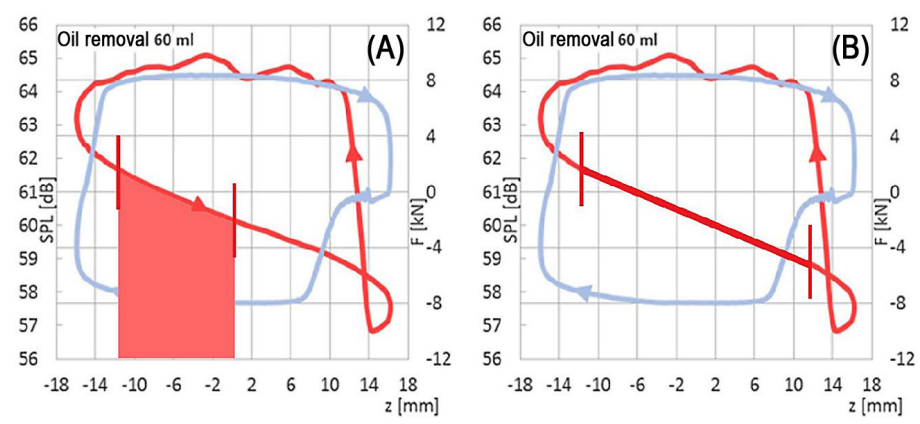

7: Fig. 7. (A) Illustration of the radiated sound criterion obtained by numerical integration. (B) Illustration of the linear regression criterion.

\begin{tabular}{|c|c|c|c|}
\hline PP 205-380 & \multicolumn{2}{|c|}{ (A) } & \\
\hline & $1 \mathrm{~Hz}$ & $2 \mathrm{~Hz}$ & $3 \mathrm{~Hz}$ \\
\hline ".0 ml" & 14,8 & 4,6 & $-0,4$ \\
\hline "-10 ml" & 11,0 & 5,6 & 2,4 \\
\hline "-25 ml" & 4,6 & 1,1 & $-0,3$ \\
\hline "-50 ml" & 1,1 & $-3,0$ & $-4,3$ \\
\hline "-60 ml" & $-1,2$ & $-6,6$ & $-4,1$ \\
\hline
\end{tabular}

\begin{tabular}{|r|r|r|r|}
\hline PP 205-380 & \multicolumn{3}{|c}{$(\mathrm{B})$} \\
\hline & \multicolumn{1}{|c|}{$1 \mathrm{~Hz}$} & \multicolumn{1}{c|}{$2 \mathrm{~Hz}$} & \multicolumn{1}{c|}{$3 \mathrm{~Hz}$} \\
\hline "-0 ml" & 6,58 & 6,71 & 7,41 \\
\hline$"-10 \mathrm{ml}$ & 6,64 & 6,83 & 7,71 \\
\hline$"-25 \mathrm{ml}$ & 6,50 & 6,81 & 7,57 \\
\hline$"-50 \mathrm{ml}$ & 6,29 & 6,96 & 7,65 \\
\hline$"-60 \mathrm{ml}$ & 6,26 & 7,07 & 7,69 \\
\hline
\end{tabular}

8: (A) The slope of the linear regression relative to axis X. The extension phase (-12 $\mathrm{mm}$ to $12 \mathrm{~mm}$ ) of the STOS shock absorber. (B) Amount of radiated sound [dB $\mathrm{mm}$ ] in the first half of the extension phase (-12 $\mathrm{mm}$ to $0 \mathrm{~mm})$, the STOS shock absorber. Both in the frequency band 205 up to $380 \mathrm{~Hz}$.

\begin{tabular}{|c|c|c|c|c|}
\hline PP 255-470 & \multicolumn{4}{|c|}{ (A) } \\
\hline & $1 \mathrm{~Hz}$ & $2 \mathrm{~Hz}$ & $3 \mathrm{~Hz}$ & $4 \mathrm{~Hz}$ \\
\hline$"-40 \mathrm{ml}$ & $.0,3$ & $-0,4$ & $-0,7$ & $-0,2$ \\
\hline "-20 ml" & 1,1 & $-0,2$ & $.0,1$ & 0,2 \\
\hline "-0ml" & 1,6 & 1,2 & 0,2 & 0,4 \\
\hline "original" & 3,1 & 1,7 & 0,2 & 0,3 \\
\hline
\end{tabular}

\begin{tabular}{|r|r|r|r|r|}
\hline PP 255-470 & \multicolumn{4}{|c|}{ (B) } \\
\hline & \multicolumn{1}{|c|}{$1 \mathrm{~Hz}$} & \multicolumn{1}{|c|}{$2 \mathrm{~Hz}$} & \multicolumn{1}{|c|}{$3 \mathrm{~Hz}$} & \multicolumn{1}{c|}{$4 \mathrm{~Hz}$} \\
\hline "-40 ml" & 48,0 & 48,4 & 48,9 & 49,5 \\
\hline "-20 ml" & 47,6 & 47,6 & 47,9 & 48,2 \\
\hline ".0 ml" & 49,2 & 49,7 & 49,2 & 49,3 \\
\hline "original" & 50,0 & 50,9 & 53,0 & 55,7 \\
\hline
\end{tabular}

9: Fig. 9. (A) The slope of the linear regression relative to axis $X$. The compression phase (20 mm to -20 mm); the FIAT shock absorber. (B) Amount of radiated sound [dB $\mathrm{mm}$ ] fort the full stroke length (compression and tension), the FIAT shock absorber. Both in the frequency band 205 to $380 \mathrm{~Hz}$.

analysis, most significant difference among the STOS shock operation modes (levels of aeration/deaerated) occurred in the frequency range of $205-380 \mathrm{~Hz}$ (Fig. 5). The deaerated shock sound pressure curve grew in the extension phase followed by a steep decline at the beginning of the compression phase. In the case of aerated shock, the sound pressure curve declined in the extension phase and steeply grew at the compression phase beginning. However, the synchronous filtration curves for the Fiat shock did not show any hint of a rule-the shapes of the curves seemed random (Fig. 6).

To quantify the differences of the curve shapes, two criteria were applied. The first one evaluated a slope of the linear regression relative to axis $\mathrm{X}$ (Fig. 7A); the other approach counted radiated sound 
amount by numerical integration (Fig. 7B) of selected part of the sound level curve. These criteria were applied only to the specific part of the whole stroke, while these intervals were chosen individually for each type of the shock absorber assessed. The linear regression criterion and radiated sound criterion were counted on: the first half of the extension part of the stroke; the second half of the extension part; the first half of the compression part; the second half of the compression part; full extension part and full compression part of the stroke.

The correlation between the amount of aeration (volume of the removed oil), the slope of the linear regression, and sound energy is shown in Fig. 8A, and Fig. 8B respectively. The most significant relationship between aeration and the slopes was found in the frequency range $205-380 \mathrm{~Hz}$ through the part of the extension stroke phase. But relationship between sound energy and the aeration level differed between $1 \mathrm{~Hz}$ and $2 \mathrm{~Hz}$ with $3 \mathrm{~Hz}$ among any investigated frequencies bands.

The same diagnostic criteria were applied to the acoustic data of the Fiat shock absorber. The curves from the synchronous filtration did not carry any information about aeration beside the case of the STOS shock. But both diagnostic criteria could indicate the amount of aeration in the frequency range $255-470 \mathrm{~Hz}$, especially at the excitation frequencies of 1 and $2 \mathrm{~Hz}$ (Fig. 9A and Fig. 9B).

\section{DISCUSSION}

The presumed differences of the radiated noise between the properly working shock absorber and malfunctioning the shock absorber were measured and analysed. The significant peaks of the frequency spectrum laid up to $800 \mathrm{~Hz}$ which is in accordance with the literature. Also, the specific noise radiation is correlated with position of the piston at the certain stroke phase. As the diagnostic criterion of aeration, the linear regression slope assessment of the radiated noise (with the synchronous filtration applied) can be used. The criterion may identify the drop of the radiated noise at the specific part of the stroke phase in case of the aerated shock. This noise decrease may be related to the drop of the damping force where the shock does not work properly. The criterion based on the assessment of the amount of sound radiated may indicate aeration too, but it could be used only for robust constructed shock absorbers with the stronger acoustic radiation. Due to differences in shock absorber internal design, the typical acoustic radiation of aerated shocks differs for each shock absorber model. The difference can be found on a specific frequency band, at specific excitation frequencies or at a specific phase of the stroke, these must be found individually for the shock absorber. For diagnostics, it is necessary to compare assessed shock absorber with a standard properly working shock absorber of the same model. This paper therefore provides possible diagnostic criteria only for hereabouts experimentally tested shock absorbers. However, the described procedure could be used for virtually any hydraulic shock absorber diagnostics.

The limitation of the experiments can be found in using the adaptive and the original Fiat shock absorber. The adaptive version of the shock had a modified construction; its acoustic radiation and dumping characteristics were slightly different that in case of the original shock. The comparison between the adaptive and the original shock must take these facts into account.

\section{CONCLUSION}

Aeration of the shock absorbers changes the shock absorber radiated noise while these differences are measurable and quantifiable. The noise of deaerated and aerated shock absorbers was measured by a sound meter. A deep noise analysis of the acoustic signals of the STOS shock absorber showed greater differences at the beginning of the compression phase of the cycle. The noise of the aerated shock absorber dramatically declined mainly in the frequencies between 205 and $380 \mathrm{~Hz}$. In case of Fiat shock absorber, more sound energy was radiated in the frequencies from 255 to $470 \mathrm{~Hz}$ when the shock was deaerated. These differences were quantified by comparison of radiated amount of sound and by comparison of linear regression of the synchronous filtration curves. These offered diagnostic criteria can be used as a basis for the new acoustic method. This fast and cheap non-contact method may assess the proper function of the shocks, which may be applied in the field of the shock absorber development.

The accuracy of the diagnostic method could be further increased by measurement in the better acoustic environment. One of the limitations of the study, especially in case of smaller FIAT shock absorber, was high background noise of the Inova actuator. Therefore, the background noise interferes with noise of the assessed shock absorber. However, analysis of the frequency spectrum with application of the synchronous filtration could supress negative effect of the background noise in satisfactory way for diagnostic purposes.

\section{Acknowledgment}

The research leading to these results has received funding from the MEYS under the National Sustainability Programme I (Project LO1202). 


\section{REFERENCES}

BENAZIZ, M., NACIVET, S. and THOUVEREZ, F. 2015. A Shock Absorber Model for Structure-Borne Noise Analyses. Journal of Sound And Vibration, 349(August): 177-194.

BENAZIZ, M., NACIVET, S., DEAK, J. and THOUVEREZ, F. 2013. Double Tube Shock Absorber Model for Noise and Vibration Analysis. SAE International Journal of Passenger Cars-Mechanical Systems 6 (2013-01-1912): 1177-1185.

DIXON, J. C. 2007. The Shock Absorber Handbook. $2^{\text {nd }}$ Edition. Chichester: John Wiley.

HUANG, H. B., LI, R. X., HUANG, X. R., YANG, M. L. and DING, P. D. 2015. Sound quality evaluation of vehicle suspension shock absorber rattling noise based on the Wigner-Ville distribution. Applied Acoustics, 100(2015): 18-25.

LAUWERYS, X., AUGUSZTINOVICZ, F., MAES, M. and NAGY, G. 2000. Identification and Reduction of Sound Sources in Wheel Suspensions. SAE Technical Paper 2000-01-1437. SAE International.

LUO, F. and ZHANG, X. L. 2014. "A Review of Aeration and Cavitation Phenomena in the Hydraulic Shock Absorber." Applied Mechanics and Materials, 536-537(2014): 1369-1373.

YUNG, V. Y. B. and DAVID, J. C. 2006. Modelling High Frequency Force Behaviour Of Hydraulic Automotive Dampers. Vehicle System Dynamics, 44(1): 1-31. 